$\mathrm{T}$ The initial part of this issue is devoted to considerations of infection by the respiratory syncytial virus, an issue which has been the subject of hotly contested correspondence ${ }^{1,2}$ following our publication of the recommendations for prophylaxis against the virus made following a meeting of the British Paediatric Cardiac Association, ${ }^{3}$ now the British Congenital Cardiac Association. In addition to the manuscripts that resulted from the symposium held at the meeting of the European Association for Paediatric Cardiology held in Munich in May of 2004, we are also pleased to publish an original article submitted over the same period from the Royal Liverpool Children's Hospital. We are grateful, however, to Tim Feltes and his colleagues for assembling the material that forms the basis of the papers resulting from the meeting in Munich, and we are the more pleased that
Tim himself, as guest editor, has agreed to introduce this important topic in the pages of the Journal.

Robert H. Anderson

Editor-in-Chief

\section{References}

1. Onuzo O. Re: Recommendation for the use of palivizumab as prophylaxis against respiratory syncytial virus in infants with congenital cardiac disease. Cardiol Young 2004; 14: 469.

2. Keeton B. Re: Recommendation for the use of palivizumab as prophylaxis against respiratory syncytial virus in infants with congenital cardiac disease. Cardiol Young 2004; 14: 469.

3. Tulloh R, Marsh M, Blackburn M, et al. Recommendations for the use of palivizumab as prophylaxis against respiratory syncytial virus in infants with congenital cardiac disease. Cardiol Young 2003; 13: 420-423.

\title{
The impact of infection by the respiratory syncytial virus in infants and young children with congenital cardiac disease
}

A

STATE-OF-THE-ART SATELLITE SYMPOSIUM, entitled "Cardiopulmonary complications following respiratory infection in infants with congenital heart disease”, was held during the Annual Meeting of the Association for European Paediatric Cardiology held in May, 2004, in Munich, Germany. At this symposium, a faculty of experts from Europe and the United States of America discussed the impact of infection with the respiratory syncytial virus on the cardiopulmonary system of infants and young children with congenital cardiac disease, as well as strategies to prevent the occurrence of such potentially life-threatening infections. Also in Munich, at the same time, a European forum was held to discuss clinical management, where an experienced and wellrespected group of paediatric cardiologists discussed their views on prophylaxis of respiratory syncytial virus in young children with congenital cardiac disease.
The widespread interest, and positive feedback, expressed by the delegates who attended the symposium, combined with many recent clinical advances in this interesting area, prompted the faculty of this symposium, who were also committee members of the European forum, to collect together their views for publication as a series of papers in "Cardiology in the Young".

In this series, we first discuss the pathogen, providing the reader with a basic knowledge of the respiratory syncytial virus, increasingly recognised as the leading cause of infection of the lower respiratory tract in infants and young children, and the single most important cause of hospitalisation during the first year of life. We identify the groups of patients at greatest risk of complications from infection, focusing in particular on children with congenital cardiac disease. We then turn to look at the vulnerability of the 
host, with a detailed review of the pulmonary effects of the respiratory syncytial virus on the infant lung. Here, we explain why the patient with a congenitally malformed heart disease is particularly susceptible to the acute complications of bronchiolitis produced by the respiratory syncytial virus. We also examine recent data reporting long-term respiratory morbidity associated with infection by the virus. Prophylaxis against the virus with the monoclonal antibody, palivizumab, is also reviewed in-depth, in terms of both immediate and potential long-term benefits. Finally, we report the recommendations made for prevention of infection of young children with congenital heart disease by the virus that resulted from our European forum on clinical management.

It is our hope that the reader will find the information contained in these papers both interesting and compelling, not least because we cover literature not typically reviewed by the paediatric cardiologist, for example neonatology, pulmonary medicine, and infectious disease. We also anticipate that the clinical recommendations will prove helpful in facilitating decision-making in the care and management of patients at high risk for infection by the respiratory syncytial virus, and that he or she will be inspired to search for new ways to improve the care of future generations.

Timothy F. Feltes Section of Pediatric Cardiology Obio State University and The Heart Center at Children's Hospital 700 Children's Drive, Columbus, OH 43205

United States of America

Tel: +16147222565

Fax: + 16147222549

E-mail: tfeltes@chi.osu.edu 